\title{
Soot on Snow experiment: bidirectional reflectance factor measurements of contaminated snow
}

\author{
J. I. Peltoniemi ${ }^{1,2}$, M. Gritsevich ${ }^{1,2,8}$, T. Hakala ${ }^{1}$, P. Dagsson-Waldhauserová ${ }^{5,6,7}$, Ó. Arnalds $^{6}$, K. Anttila ${ }^{1,3}$, \\ H.-R. Hannula ${ }^{4}$, N. Kivekäs ${ }^{3}$, H. Lihavainen ${ }^{3}$, O. Meinander ${ }^{3}$, J. Svensson ${ }^{3,9}$, A. Virkkula ${ }^{3}$, and G. de Leeuw Le $^{2,3}$ \\ ${ }^{1}$ Finnish Geospatial Research Institute (FGI), Geodeetinrinne 2, Masala, Finland \\ ${ }^{2}$ Department of Physics, University of Helsinki, P.O. Box 64, Helsinki, Finland \\ ${ }^{3}$ Finnish Meteorological Institute, P.O. Box 503, Helsinki, Finland \\ ${ }^{4}$ Finnish Meteorological Institute Arctic Research Centre, Tähteläntie 62, Sodankylä, Finland \\ ${ }^{5}$ Agricultural University of Iceland, Faculty of Environmental Sciences, Hvanneyri, Iceland \\ ${ }^{6}$ University of Iceland, Faculty of Physical Sciences and Faculty of Earth Sciences, Reykjavik, Iceland \\ ${ }^{7}$ Czech University of Life Sciences Prague, Faculty of Environmental Sciences, Department of Ecology, \\ Prague, Czech Republic \\ ${ }^{8}$ Ural Federal University, Institute of Physics and Technology, Ekaterinburg, Russia \\ ${ }^{9}$ Department of Environmental Science, University of Helsinki, Helsinki, Finland
}

Correspondence to: J. I. Peltoniemi (jouni.peltoniemi@helsinki.fi)

Received: 24 April 2015 - Published in The Cryosphere Discuss.: 3 June 2015

Revised: 26 October 2015 - Accepted: 16 November 2015 - Published: 11 December 2015

\begin{abstract}
In order to quantify the effects of absorbing contaminants on snow, a series of spectral reflectance measurements were conducted. Chimney soot, volcanic sand, and glaciogenic silt were deposited on a natural snow surface in a controlled way as a part of the Soot on Snow (SoS) campaign. The bidirectional reflectance factors of these soiled surfaces and untouched snow were measured using the Finnish Geodetic Institute's Field Goniospectropolariradiometer, FIGIFIGO.

A remarkable feature is the fact that the absorbing contaminants on snow enhanced the metamorphism of snow under strong sunlight in our experiments. Immediately after deposition, the contaminated snow surface appeared darker than the natural snow in all viewing directions, but the absorbing particles sank deep into the snow in minutes. The nadir measurement remained the darkest, but at larger zenith angles, the surface of the contaminated snow changed back to almost as white as clean snow. Thus, for a ground observer the darkening caused by impurities can be completely invisible, overestimating the albedo, but a nadir-observing satellite sees the darkest points, underestimating the albedo. Through a reciprocity argument, we predict that at noon, the albedo perturbation should be lower than in the morning or after-
\end{abstract}

noon. When sunlight stimulates sinking more than melting, the albedo should be higher in the afternoon than in the morning, and vice versa when melting dominates. However, differences in the hydrophobic properties, porosity, clumping, or size of the impurities may cause different results than observed in these measurements.

\section{Introduction}

Snowpacks and ice sheets around the globe play a crucial role in the Earth's radiation budget. The albedo of snow depends, among other factors, on its physical properties, such as, for example, snow grain size, shape, packing, topography, and snow thickness. It is usually significantly higher compared to that of other natural surfaces (Peltoniemi et al., 2015).

With the rapidly-growing number of techniques for Earth observation, the accelerating shrinkage of snowpacks and glaciers over the past decades has been confirmed based on dedicated satellite and in situ measurements. In order to reliably interpret these observations and forecast further changes in snow cover, there is a need to increase existing knowledge on the processes affecting the state of snow. Deposition of 
light-absorbing impurities on the surface of snow decreases its reflectance (Warren and Wiscombe, 1980; Clarke and Noone, 1985; Dumont et al., 2014) and accelerates snowmelt (Bond et al., 2013).

The presence of light-absorbing impurities in the snow may cause dramatic effects even on fresh snow surfaces, lowering their reflectivity below the typical range of 0.7-0.9. Aerosol particles originating from both anthropogenic and natural sources can be transported over very long distances.

Measurements of actual impurity concentrations in snowpacks and glaciers have been conducted on different spatial and temporal scales in natural conditions by for example Clarke and Noone (1985); McConnell et al. (2007); Ming et al. (2008); Xu et al. (2009); Forsström et al. (2009); Doherty et al. (2010); Kaspari et al. (2011); Bisiaux et al. (2012); Meinander et al. (2013); Svensson et al. (2013); Dagsson-Waldhauserova et al. (2015). Furthermore, to observe the effects of impurities on the snow, several experimental studies have been conducted (Conway et al., 1996; Brandt et al., 2011; Hadley and Kirchstetter, 2012). Their setups have been carefully reviewed by Svensson et al. (2015). The reflectance of natural snow has already been measured in several ways, for instance in Piironen et al. (2000); Aoki et al. (2000); Painter et al. (2003); Kaasalainen et al. (2006); Bourgeois et al. (2006); Peltoniemi et al. (2009); Tanikawa et al. (2014), and that of carbon particles alone by Sasse and Peltoniemi (1995).

The reflectance of natural snow has been modelled by many, using various combinations of radiative transfer, raytracing, and electromagnetic techniques (Wiscombe and Warren, 1980; Aoki et al., 2000; Tanikawa et al., 2006; Peltoniemi, 2007; Lyapustin et al., 2010; Räisänen et al., 2015). Snow contaminated with impurities has been modelled for example by Warren and Wiscombe (1980); Flanner et al. (2007); Kokhanovsky (2013). These models can usually provide a first-order approximation for the distribution of the reflected radiation and effects of impurities. However, all the models contain uncertainties in modelling the shape of the snow grains, their size distributions, three-dimensional structure of the snowpack, and the distribution of impurities. These factors can change the albedo by several percent, and at certain viewing directions, the reflectance may change more than $10 \%$ (Peltoniemi, 2007). None of the models have yet been able to explain the observed polarization features (Peltoniemi et al., 2010b).

The Finnish Meteorological Institute (FMI) organized a series of experiments, using a different approach than the cited studies (Meinander et al., 2014; Svensson et al., 2015). Experiments were conducted in different regions in Finland, in 2011 and 2013, with the general aim to monitor and quantify the effects of soot on the albedo and physical properties of the snowpack. To this end, absorbing aerosols of different origins were deposited on a natural snowpack in a controlled way and the changes in the snowpack properties were measured (Meinander et al., 2014; Svensson et al., 2015). In this

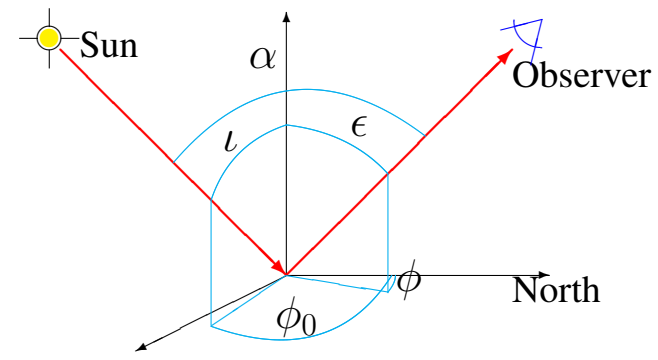

Figure 1. Definition of the angles used in surface reflectance work: $\epsilon$ and $\iota$ are the zenith angles of the emergent (observer) and incident (solar) radiation respectively (shorthand $\mu=\cos \epsilon$ and $\mu_{0}=\cos \iota$ are also used). $\phi$ and $\phi_{0}$ are the corresponding azimuth angles. The phase angle $\alpha$ is the angle between the observer and the Sun. The principal plane is fixed by the solar direction and the surface normal, while the cross plane is a vertical plane perpendicular to the principal plane.

paper we describe the measurements of the bidirectional reflectance factor (BRF) used to quantify the effects of different absorbing materials on snow using the Finnish Geodetic Institute's Field Goniospectropolariradiometer, FIGIFIGO.

\section{Methods and instruments}

The bidirectional reflectance factor (BRF for short, or $R$ in equations) is defined as the ratio of the reflected light intensity of a given target to an ideal Lambertian reflector with a spherical albedo of 1.0 under the same incident irradiation (Nicodemus et al., 1977; Hapke, 1993). The BRF can be presented as

$R\left(\mu, \mu_{0}, \phi, \phi_{0}\right)=\frac{\pi I(\mu, \phi)}{\mu_{0} F_{0}\left(\mu_{0}, \phi_{0}\right)}$,

where $F_{0}$ is the incident collimated flux and $I$ the reflected radiance; $\iota$ and $\phi_{0}$ are the zenith and azimuth angles of incidence, $\epsilon$ and $\phi$ are the zenith and azimuth angles of emergence, $\alpha$ is the phase angle that is defined as the angle between the source and observer equalling the complement of the scattering angle $(\cos \alpha=\cos \iota \cos \epsilon+\sin \iota \sin \epsilon \cos (\phi-$ $\left.\phi_{0}\right)$ ), and $\mu=\cos \epsilon, \mu_{0}=\cos \iota$ (Fig. 1). A related quantity is the bidirectional reflectance distribution function (BRDF), here denoted as $\mathcal{R}=R / \pi$. Experimentalists and practical users prefer using BRF for its more intuitive magnitude which is normalized to a perfect Lambertian reflector $R=1$. Modellers prefer BRDF for its more natural mathematical interpretation and simpler equations. For example reflected ra- 
diation can be written with $\mathcal{R}$ as

$$
\begin{aligned}
I(\mu, \phi)= & \int \mathrm{d} \mu^{\prime} \phi^{\prime} \mathcal{R}\left(\mu, \phi, \mu^{\prime}, \phi^{\prime}\right) \mu^{\prime} I\left(\mu^{\prime}, \phi^{\prime}\right) \\
= & \int \mathrm{d} \mu^{\prime} \phi^{\prime} \mathcal{R}\left(\mu, \phi, \mu^{\prime}, \phi^{\prime}\right) \mu^{\prime} I_{\operatorname{Diff}}\left(\mu^{\prime}, \phi^{\prime}\right) \\
& +\mathcal{R}\left(\mu, \phi, \mu_{0}, \phi_{0}\right) \mu_{0} F_{0}\left(\mu_{0}, \phi_{0}\right),
\end{aligned}
$$

where $I_{\text {Diff }}$ represents diffuse skylight.

For the detailed multi-angular reflectance measurements conducted within the experiment we have used the FIGIFIGO, Finnish Geodetic Institute's Field Goniospectropolariradiometer (Peltoniemi et al., 2009, 2010a, b, 2014; Suomalainen et al., 2009; Hakala et al., 2010, 2014), shown in Fig. 2. The primary sensor of the FIGIFIGO is an ASD FieldSpec Pro FR Spectroradiometer (Analytical Spectral Devices Inc.) with a spectral range of 350-2500 nm, full width at half maximum of $3 \mathrm{~nm}$ from 350 to $1000 \mathrm{~nm}$, and $10 \mathrm{~nm}$ from 1000 to $2500 \mathrm{~nm}$. The spectrometer is connected to the front optics with an optical cable of a length of $3 \mathrm{~m}$. The optics is interchangeable, including normal optics with a $3^{\circ}$ field of view, and optics with a rotatable Glan-Thompson linear polarizer.

The optics are placed on top of a 1.5-2.5 m long telescope arm. At an arm length of $2.5 \mathrm{~m}$ the optics' footprint diameter is $20 \mathrm{~cm}$. The arm is equipped with an inclinometer and a motor, which allows changing of the view zenith direction by tilting the arm. The view azimuth angle is selected by turning the whole device manually. In the field conditions the orientation relative to the Sun is measured with a fish-eye camera fixed to the FIGIFIGO frame, and the direction of the Sun is calculated based on GPS positioning and time. The fish-eye camera also saves images of the sky periodically for postprocessing sky monitoring purposes. Solar irradiance is additionally monitored by a silicon pyranometer (SP Lite, Kipp and Zonen) during the measurement.

The FIGIFIGO field measurement process was carried out as follows.

1. The target was selected and prepared (see next section for details).

2. The system was mounted and started. At least 20 min was allowed for the spectrometer to warm up, in most cases more.

3. The sensor was optimized and a reference measurement taken using a white $25 \mathrm{~cm}$ Spectralon ${ }^{\circledR}$ panel by Labsphere with a nominal reflectance of $99 \%$. The panel was carefully levelled, and its cleanness checked. Any loose dust or water drops were removed by compressed air.

4. The contribution of diffuse light from the sky, clouds, and the environment ( $M_{\mathrm{D}}$ in Eq. (3) below) was measured by shadowing the target from direct sunlight using a small screen.

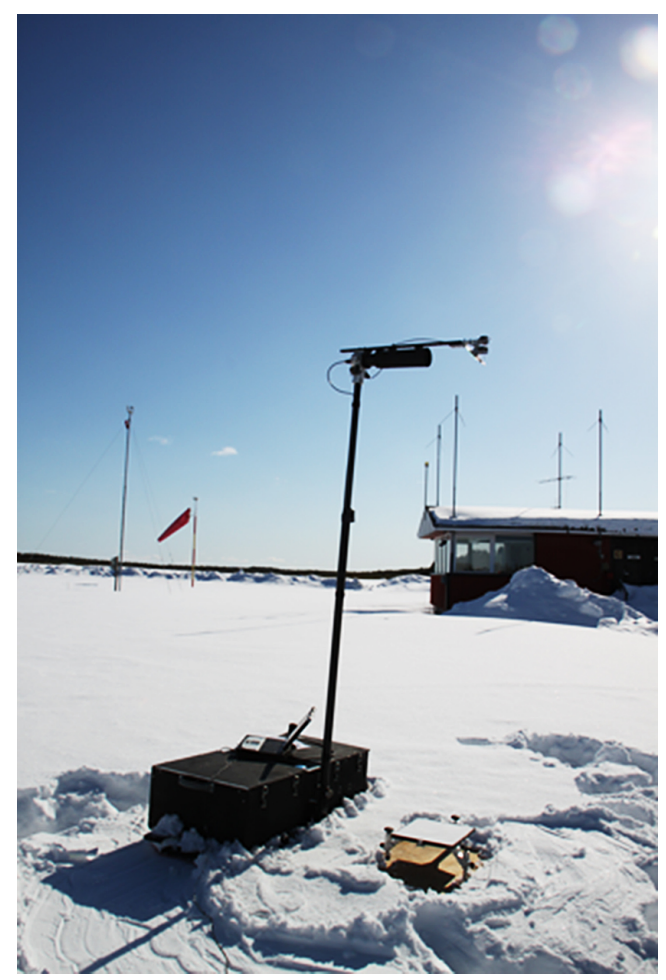

Figure 2. FIGIFIGO at the SoS test site at Sodankylä Airport. A clean snow sample has been measured, and the last reference measurement of the white Spectralon ${ }^{\circledR}$ panel is being taken. Deep and soft snow complicated the usability of FIGIFIGO. While the movements in the snow left significant traces, the target area under the instrument footprint was carefully kept untouched during the measurement.

5. Then, the target reflectance was measured, by automatically turning the zenith arm and manual azimuthal rotations.

6. The Spectralon ${ }^{\circledR}$ white reference was remeasured several times during the measurements and at the end of the sequence, depending on illumination stability.

7. The documentation was completed, the data file was closed, and the system moved to the next target or dismounted.

In laboratory the diffuse part was not needed, but one more step to set-up the illumination with a $1000 \mathrm{~W}$ QTH (quartz tungsten halogen) lamp by Oriel was required. The data were checked and erratic data removed. Unstable data were marked as unstable. The spectral measurement was normalized with white reference data and the diffuse part subtracted. For unpolarized measurements, the data renormalization is 
performed as follows:

$R\left(\mu, \phi, \mu_{0}, \phi_{0}\right)=$

$\frac{M\left(\mu, \phi, \mu_{0}, \phi_{0}\right)-M_{\mathrm{D}}\left(1, \mu_{0}, \phi_{0}\right)}{S\left(\mu, \phi, \mu_{0}, \phi_{0}\right)-S_{\mathrm{D}}\left(1, \mu_{0}, \phi_{0}\right)} R_{\mathrm{ref}}\left(\mu, \phi, \mu_{0}, \phi_{0}\right)$,

where $M$ is the measurement of the target, $M_{\mathrm{D}}$ the estimate for the diffuse part, $S$ the measurement of the Spectralon ${ }^{\circledR}$ standard, $S_{\mathrm{D}}$ the diffuse part of that, and $R_{\text {ref }}$ the laboratorymeasured value of the reflectance of the Spectralon ${ }^{\circledR}$ (Peltoniemi et al., 2014). Because the reference values are not measured simultaneously for each measurement, but only at the start and end (if possible), the reference values were interpolated from the nearest points based on time. The diffuse light estimate is based on nadir measurement only, yielding a $1-5 \%$ uncertainty concentrated in the blue end. With polarization the procedure involves more phases (see, e.g. Peltoniemi et al., 2015), but here polarization data are not shown.

\section{Samples}

The major contributions to the absorption of light in nature originate from volcanic sand, glaciogenic silt, and natural and anthropogenic sources of black and brown carbon. For the purposes of our experiment, the components described below were primarily selected. See also Table 1 and Fig. 3.

\subsection{Volcanic sand}

Volcanic sand was collected from the Mýrdalssandur dust source in southern Iceland in November 2012. This material has been mixed by aeolian processes, resulting in an enriched sand proportion as the silt-sized material is lost as dust along the way. The sample is a near-black mixture of volcanic ash of glaciofluvial nature, originating from under the Mýrdalsjökull glacier, which may be mixed with the ash of the Eyjafjallajökull eruption in 2010 and the Grimsvötn eruption in 2011. It represents well the material re-suspended in the most active dust source in southern Iceland and deposited on glaciers or snow in south and south-east Iceland. Atmospheric dust in Iceland comes from two different dust sources. The first are the extensive sandy deserts. Many of these produce little dust per unit area (very variable because of many types of sandy surfaces), but due to their extent, they are an important dust source. The second main source of dust from Iceland are dust plume areas with high dust productivity per unit area, located mostly near glaciers and along glacial river beds. The volcanic dust is mostly made of basaltic to andesitic poorly crystallized glass particles, dark to black in colour. The density is about $0.9 \mathrm{~g} \mathrm{~cm}^{-3}$.

\subsection{Glaciogenic silt}

The sample was collected from the glacial river Múlakvisl, about $10 \mathrm{~km}$ from the Mýrdalsjökull glacier in southern Ice-

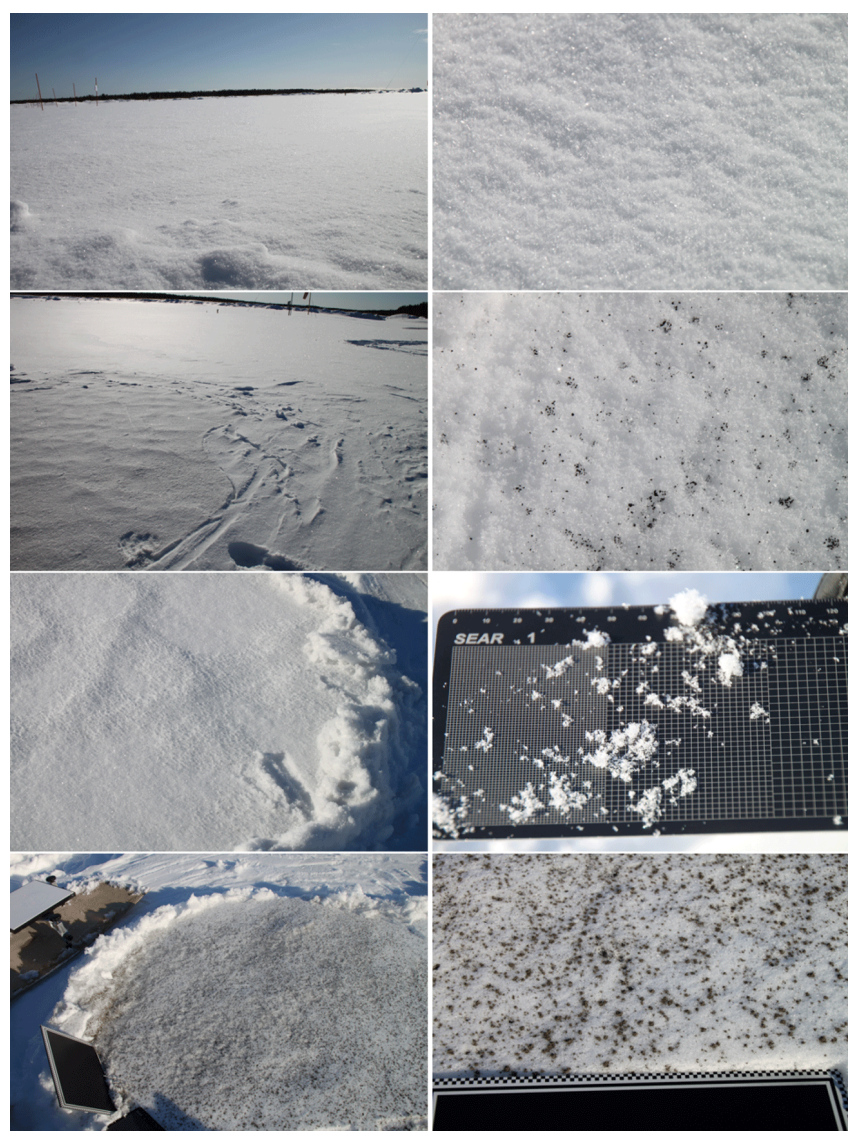

Figure 3. Photographs of the samples. On the left is an overview; the right shows some details. Starting from the top photographs, clean snow on 4 April 2013 is shown, snow deposited with volcanic ash on 3 April 2013, snow deposited with chimney soot on 4 April 2013, and on the bottom, snow deposited with glaciogenic silt on 4 April 2013 is shown.

land, one of the main rivers draining the glacier, and the materials originates from the Katla volcanic system under the glacier. The glaciogenic silt is brighter in colour than the sand. It is light-brown to slightly yellowish in colour and it consists mainly of silt and some coarse clay-sized particles, which are easily re-suspended on a daily basis on dry days. This material can be transported and deposited on the local glaciers as well as being transported by wind several hundreds of kilometres towards Europe. The density is about $1.2 \mathrm{~g} \mathrm{~cm}^{-3}$.

\subsection{Chimney soot}

Soot was acquired from a chimney-sweeping company in Helsinki, which collected the soot from residential buildings that use small-scale wood and oil burning for heating. The soot was blown onto the snow surface as explained by Svensson et al. (2015). Here the soot was used as a proxy of black carbon and also contained some brown carbon. 
Table 1. List of the samples measured using FIGIFIGO during the SoS campaign at Sodankylä Airport. Numbers in parentheses are from unstable data; double parentheses denote very unstable data, due to increasing cloudiness. ID means the name by which the measurement is found in the data base, SZA is the solar zenith angle, and PAR alb is the albedo integrated over the photosynthetically active range.

\begin{tabular}{llllll}
\hline Start time & Sample & SZA & ID & Albedo & PAR alb \\
\hline 3 Apr 2013 11:33 & natural soft snow & 63 & 1 & 0.80 & 0.96 \\
3 Apr 2013 12:25 & snow + volcanic sand, 8 g & 62 & 56 & 0.78 & 0.93 \\
3 Apr 2013 13:23 & snow + volcanic sand, 8 g & 62 & 2 & $(0.72)$ & $(0.86)$ \\
3 Apr 2013 14:42 & natural snow & 64 & 3 & 0.74 & 0.87 \\
\hline 4 Apr 2013 09:56 & snow + soot, 1 kg/+new snow $<1 \mathrm{~mm}$ & 68 & 5 & 0.68 & 0.83 \\
4 Apr 2013 10:31 & snow + soot, 1 kg/+new snow $<1 \mathrm{~mm}$ & $66 \mathrm{p}$ & $5 \mathrm{P}$ & $((0.74))$ & $((0.94))$ \\
4 Apr 2013 11:18 & snow + soot, 1 kg/+new snow $<1 \mathrm{~mm}$ & $62 \mathrm{p}$ & 55 & 0.65 & 0.80 \\
4 Apr 2013 12:39 & snow + soot, 1 kg/+new snow $<1 \mathrm{~mm}$ & $63 \mathrm{p}$ & 6 & 0.65 & 0.84 \\
4 Apr 2013 13:31 & natural snow & 62 & 7 & 0.76 & 0.94 \\
4 Apr 2013 15:05 & snow + silt, 10 g & 65 & 8 & 0.70 & 0.83 \\
4 Apr 2013 16:39 & snow + silt, 20 g & 72 & 9 & 0.46 & 0.51 \\
\hline 5 Apr 2013 11:16 & snow + silt, 20 g & 61 & 10 & 0.41 & 0.51 \\
5 Apr 2013 14:16 & snow + silt, 40 g & 62 & 11 & $(0.17)$ & $(0.20)$ \\
5 Apr 2013 15:08 & natural snow & 66 & 12 & $(0.78)$ & $(0.96)$ \\
5 Apr 2013 16:55 & snow + silt, 40 g & 74 & 13 & $((0.22))$ & $((0.23))$ \\
\hline
\end{tabular}

Table 2. The snow structure profile, 3 April 2013, 11:20 EET. Snow depth from the snowpack surface (cm), snow grain shape, hand hardness index, and snow wetness index defined according to Fierz et al. (2009). Minimum, maximum, and average snow grain size ((mm), longest axis, $0.25 \mathrm{~mm}$ resolution) as visually approximated from macro-photographs.

\begin{tabular}{llrrrrr}
\hline Depth $(\mathrm{cm})$ & Crystal shape & Hardness & Wetness & Min size $(\mathrm{mm})$ & Max size & Average size \\
\hline 3 & Ppir & 1 & 2 & 0.0 & 1.0 & 0.3 \\
16 & RGxf & 1 & 1 & 0.5 & 1.5 & 0.8 \\
20 & RGxf & 1 & 1 & 0.3 & 1.8 & 1.0 \\
31 & Fcso & 1 & 1 & 0.5 & 2.5 & 1.0 \\
39 & FCso & 2 & 1 & 0.5 & 2.3 & 1.3 \\
52 & DHcp + DHch & 1 & 1 & 0.5 & 4.0 & 1.5 \\
66 & DHcp & 4 & 1 & 0.0 & 4.3 & 2.3 \\
\hline
\end{tabular}

\subsection{Contaminated snow in Sodankylä}

Table 3. The snow density profile, measured at Sodankylä Airport near FIGIFIGO spot on 3 April 2013, 15:00 EET.

\begin{tabular}{ll}
\hline Depth $(\mathrm{cm})$ & Density $\left(\mathrm{g} \mathrm{cm}^{-3}\right)$ \\
\hline $0-5$ & 0.244 \\
$5-10$ & 0.272 \\
$10-15$ & 0.256 \\
$15-20$ & 0.248 \\
$20-25$ & 0.256 \\
$25-30$ & 0.300 \\
$30-35$ & 0.300 \\
$45-40$ & 0.244 \\
$40-45$ & 0.292 \\
$45-50$ & 0.324 \\
$50-55$ & 0.232 \\
\hline
\end{tabular}

The main experiment series of the SoS 2013 campaign took place in Sodankylä Airport, northern Finland, where specific set-ups had been build already before snow fall. In order to control the absorption in snow, the above described contaminants were deposited on snow in various ways. The main experiment and the soot depositing system are described in Svensson et al. (2015). In short, the soot was fed to a cyclone separating smaller particles to be blown into a closed chamber around the target snow where the soot slowly deposited onto the snow surface. Only one preliminary test spot made this way could be measured by FIGIFIGO. However, because the sampling area of FIGIFIGO is much smaller than that of the albedometers, it was possible to use different techniques. For most FIGIFIGO measurements, the particles were distributed manually over an area of $0.5 \mathrm{~m}^{2}$ using a salt shaker filled with a measured amount of soot. 
On the first measurement day of the campaign, 3 April 2013, a clean and smooth snow spot was selected, and its BRF was measured. After that, $8 \mathrm{~g}$ black volcanic sand was spread manually on the snow over about $0.5 \mathrm{~m}^{2}$, and the BRF measurements were acquired as quickly as possible. The measurement was repeated in the next spot similarly with $8 \mathrm{~g}$ of ash spread over $0.5 \mathrm{~m}^{2}$. The properties of the clean snow nearby are shown in Tables 2 and 3, with some photographs in Fig. 4.

During the same day (3 April), the primary experiment made its first large test spot using chimney soot. At night, a thin layer of new snow fell over the site, and all the target spots were also covered. In the morning the sky cleared, and a modest wind partially cleaned the fallen snow. The BRF of this sooted sample was measured four times on the 4 April, at different solar zenith angles, also with polarization, examining the metamorphism process. After soot was spread on the spot surface, clean untouched snow was measured nearby as a reference. Some profile pictures are shown in Fig. 5.

The measurement continued by depositing $10 \mathrm{~g}$ of glaciogenic silt over an area of $0.5 \mathrm{~m}^{2}$ of clean snow. Again some sinking happened, but the measurement was fast and the results are considered useful. After some time, another $10 \mathrm{~g}$ was spread over the same spot to make it darker, and the target was measured again.

The sample remained untouched during the night, and the next morning it was measured again. This day (5 April) was already more cloudy than the preceding ones, adding too much uncertainty to perform low concentration measurements. Thus we deposited another $20 \mathrm{~g}$ silt over the same sample, and measured the reflectance, followed by a clean snow sample taken for reference, and again a new sample of snow with $40 \mathrm{~g}$ of silt deposited over an area of $0.5 \mathrm{~m}^{2}$. The properties of the clean snow nearby are shown in Tables 4 and 5, with some photographs in Fig. 6.

The air temperature varied between $-20^{\circ} \mathrm{C}$ at night and $+5^{\circ} \mathrm{C}$ at the warmest part of the day. The clean snow temperature was several degrees below zero, from -8 to $-3{ }^{\circ} \mathrm{C}$ near the surface and around $-2{ }^{\circ} \mathrm{C}$ near the bottom. Figure 7 shows the snow and air temperatures measured at a nearby swamp by an FMI weather station. The actual temperatures at the airport site may differ a small amount.

\section{Results}

The key results are shown in Figs. 9 to 12 . Most of the features are shown in three different plots of selected measurements. On the left, the BRF is shown as a function of observer zenith and azimuth angles, integrated over the full measurement range weighed with a fixed solar spectrum; it gives a good overview of the reflected energy distribution. In the middle, the principal plane BRF curve as a function of the observer zenith angle gives more details of the directional effects, here shown in six different wavelength

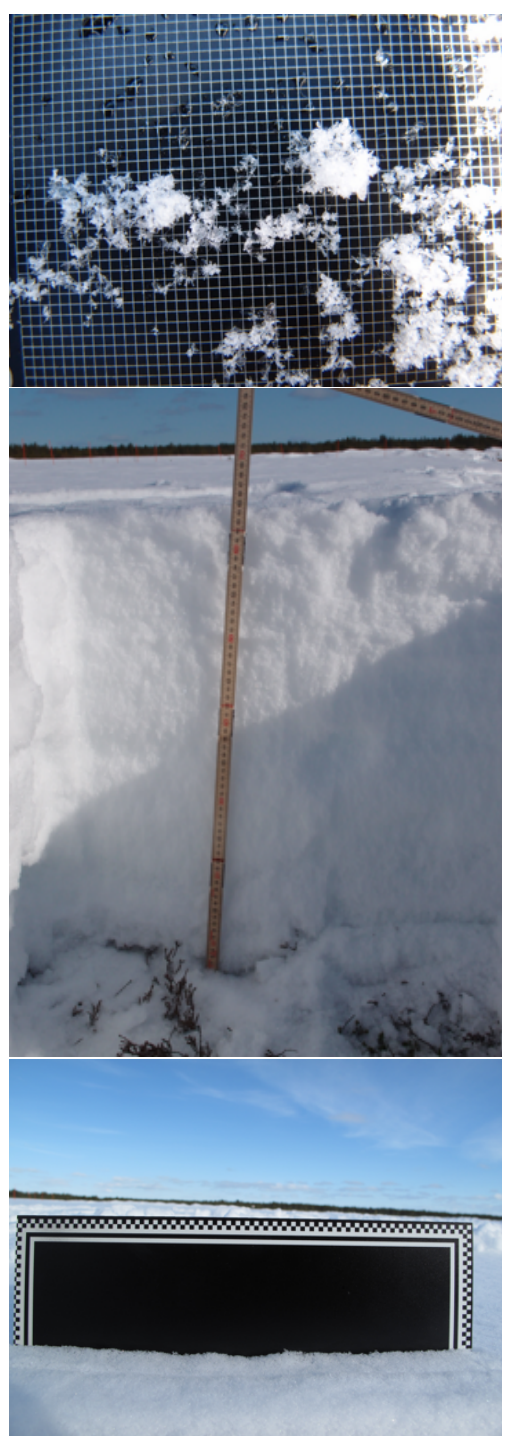

Figure 4. More snow profiles taken on the 3 April of unprocessed snow near the FIGIFIGO spot. Because of near-zero temperature, the snow crystals melt fast on the black plate, and the smallest details and grains have already disappeared.

bands: violet $443 \mathrm{~nm}$, green $565 \mathrm{~nm}$, red $670 \mathrm{~nm}$, NIR (nearinfrared) $865 \mathrm{~nm}$, SWIR (short-wave infrared) $1250 \mathrm{~nm}$, and SWIR $1555 \mathrm{~nm}$, each with a bandwidth of $20 \mathrm{~nm}$ in visual wavelengths and $50 \mathrm{~nm}$ in IR. On the right, the spectral albedo integrated over all directions using semi-polynomial inter/extrapolation is compared with the nadir spectrum. Full data with many different plots can be downloaded on our website $^{1}$. The first set (Fig. 9) shows the 3 April 11:33 EET (Eastern European Time) measurement of clean snow, the

\footnotetext{
${ }^{1}$ All the measurement data are stored in FGI's Reflectance Library and are available at https://webdisk.kotisivut.com/fgi/ Reflectance_Library/2013SoS/. Ask the authors for the password to access the data.
} 


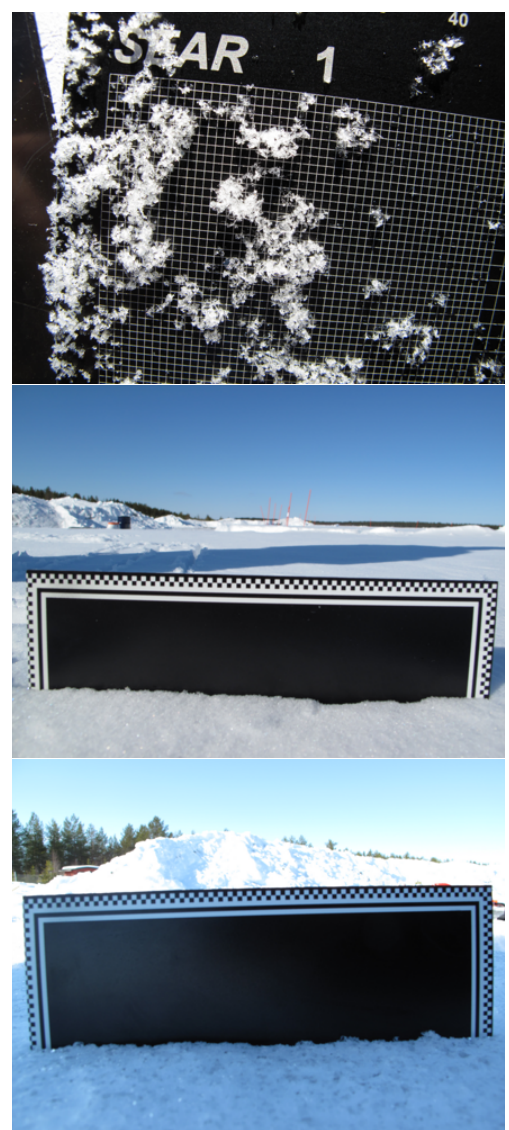

Figure 5. More snow profiles taken on the 4 April of unprocessed snow near the FIGIFIGO spot, plus one profile from the sample sooted on the 3 April, and measured on the 4 April.

Table 4. Snow depth profile measured from a snow pit on 5 April 2013.

\begin{tabular}{lll}
\hline Depth $(\mathrm{cm})$ & Crystal shape & \\
\hline surface & PPir & $\begin{array}{l}\text { small crystalline, not dendritic, } \\
\text { smaller than 3 Apr } \\
\text { more icy, more granular } \\
\text { even more icy, grains larger }\end{array}$ \\
4.5 & RGxf & similar \\
12.5 & FCsf & ice lens below harder \\
15 & FCco & rough icy grains \\
19 & MFcf & larger icy grains \\
29 & FCso & below harder \\
32 & FCso & larger icy grains \\
42 & FCso+DHcp & larger faceted icy grains \\
47 & DHcp+DHch & larger icy grains, planar \\
59 & DHcp+DHch & icy deep hoar \\
64 & DHcp+DHch & . \\
\hline
\end{tabular}

12:25 measurement of the snow contaminated by $8 \mathrm{~g}$ volcanic sand per $0.5 \mathrm{~m}^{2}$, then the 13:22 measurement of $8 \mathrm{~g}$ volcanic sand per $0.5 \mathrm{~m}^{2}$, and lastly, the pure volcanic sand sample measured in the laboratory. The second set (Fig. 10) shows the measurements from a sooted snow sample on 4 April at 09:56, and at 11:38, natural snow at 13:31, and

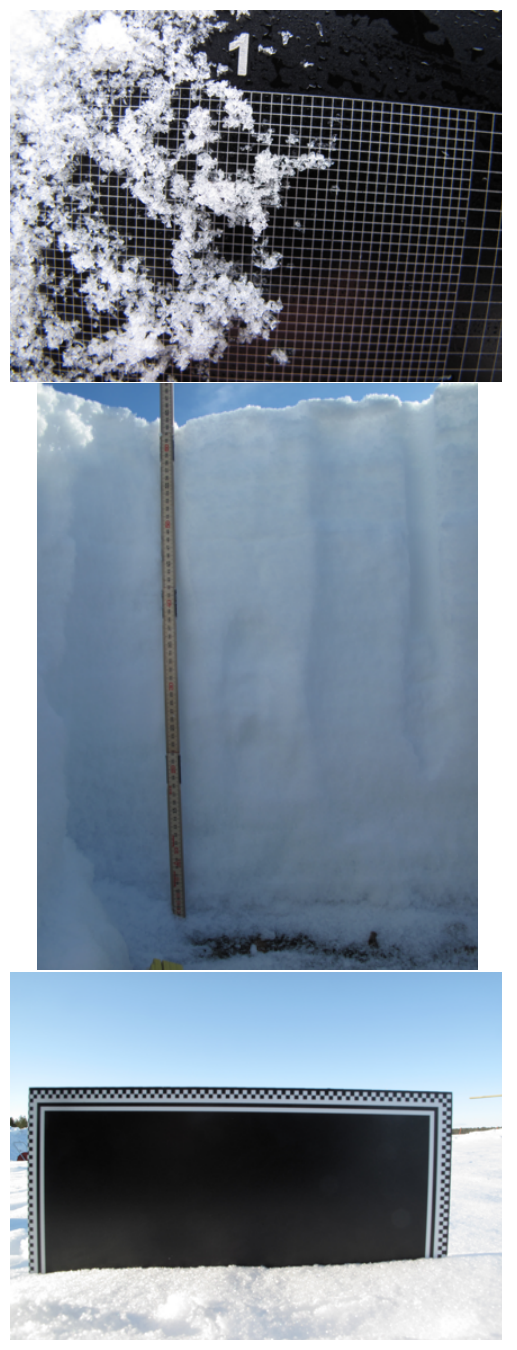

Figure 6. More snow profiles taken on the 5 April of unprocessed snow near the FIGIFIGO spot.

Table 5. The snow density profile, measured at the airport near the FIGIFIGO spot on 5 April 2013.

\begin{tabular}{lll}
\hline Depth $(\mathrm{cm})$ & Density $\left(\mathrm{g} \mathrm{cm}^{-3}\right)$ & Comment \\
\hline $0-5$ & 0.29 & icy \\
$5-10$ & 0.36 & harder \\
$10-15$ & 0.28 & \\
$15-20$ & 0.24 & \\
$20-25$ & 0.24 & \\
$25-30$ & 0.30 & \\
$30-35$ & 0.30 & \\
$35-40$ & 0.25 & \\
$40-45$ & 0.28 & \\
$45-50$ & 0.28 & \\
$50-55$ & 0.25 & \\
$55-60$ & 0.24 & \\
$59-64$ & 0.22 & \\
\hline
\end{tabular}




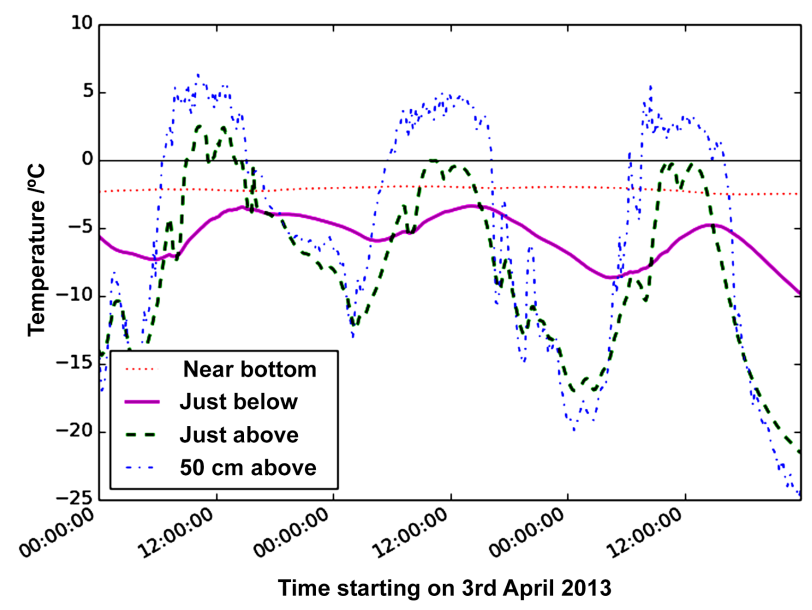

Figure 7. The snow and air temperatures measured by an FMI weather station at a swamp near Tähtelä, Sodankylä, a few kilometres from the airport. The bottom value is measured at the interface between snow and the ground. "Just below" refers to $1-9 \mathrm{~cm}$ below the snow surface, and "just above" refers to 9-1 cm above.
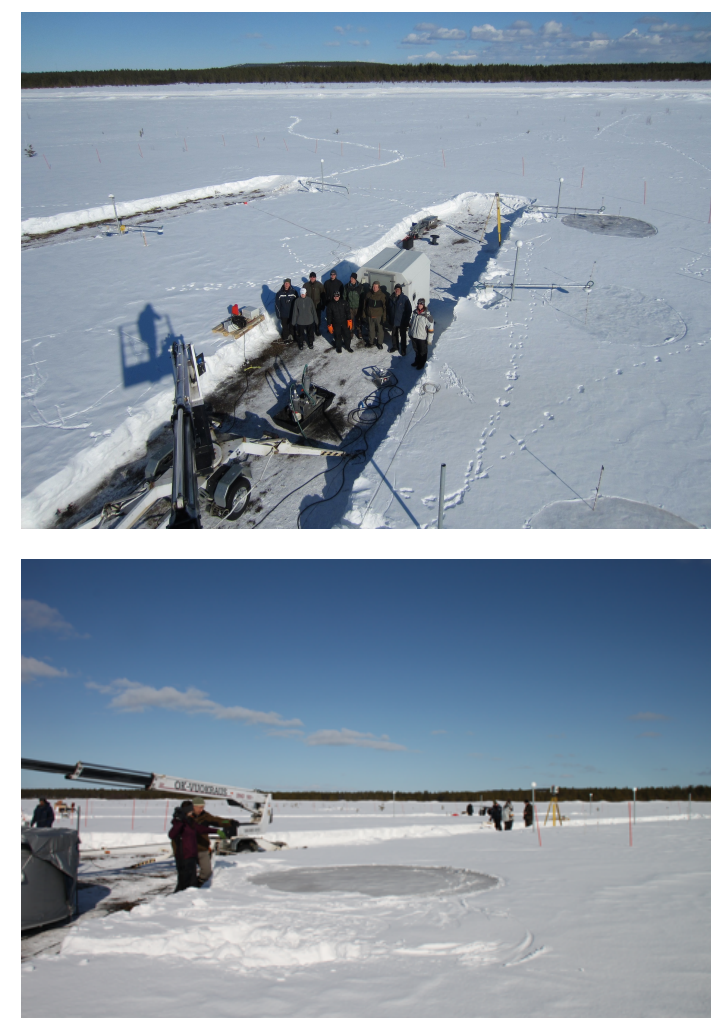

Figure 8. The SoS experiment system at Sodankylä Airport. Top photo by Rae Ellen Bichell.

the laboratory measurement of pure soot. The 12:39 results are similar to the 11:18 measurements, and are not shown. During the 10:31 measurement, changes were too large to obtain a full data set. The third set (Fig. 11) shows the ef- fects of fine silt on snow, first $10 \mathrm{~g}$ of silt per $0.5 \mathrm{~m}^{2}$ on the 4 April at 15:05, then $40 \mathrm{~g}$ of silt per $0.5 \mathrm{~m}^{2}$ at $16: 29$, the third same sample on the 5th of April at 11:16, and lastly, the pure silt measured in the laboratory. In the laboratory, about $1 \mathrm{~cm}$ thick layer of the material was spread evenly on a black surface.

To demonstrate the fast metamorphism and sinking effects, Fig. 12 shows data from three measurements, first the principal plane BRF taken at the beginning of the measurements, second the principal plane BRF at the end of the measurements, and finally a time plot of all nadir BRF during one measurement's sequence. The measurements of clean snow on the 5 April started at 15:08, snow with $40 \mathrm{~g}$ of silt on the 5 April at 14:06, and the same $40 \mathrm{~g}$ of silt at a larger zenith angle started at 16:55.

\section{Discussion}

The BRF of snow has been well characterized by many authors, see e.g. a review by Peltoniemi et al. (2010b). The spectral shape is strongly influenced by the grain size, and weakly by the presence of liquid water, impurities, and the surface below. Directionally, snow is a forward scatterer, with a weak bowl shape in the visible band, and a much deeper bowl in the NIR bands. The directional dependence is most related to the grain shape and topography. Rough snow surfaces scatter more backwards and less sideways than smooth surfaces. Also the irregularity of grains increases the backscattering slightly. The present results do not contradict this. Below, the new effects of impurities are analysed in more detail.

Typically, contaminated snow darkens the most in the nadir, and the least in the forward direction. Especially, when the black contaminants sink deeper into the snow, the bowl shape of the BRF is enhanced, and from larger zenith angles the snow looks brighter. Thus, from the normal human "feeton-the-ground" perspective, the differences between contaminated and clean snow almost disappear, while from the nadir the contaminated snow can still be almost black. The directional effects of contaminants are clearly distinguishable from grain size, shape, and topography effects only when the concentration of impurities is high and the surface is visibly darker. At more natural $<$ ppm concentrations the directional effect is probably in the limit of significance. The strong forward spike in the 4 April 09:56 measurement (Fig. 10, top) is typical for lower solar angles (here $68^{\circ}$ ), but may have been enhanced by a tiny amount of fresh snow. Another angular effect may be seen between the 4 April 16:30 measurement, with a starting solar zenith angle of $72^{\circ}$, and the 5 April 11:56 measurement, starting at $61^{\circ}$. At the solar zenith angle of $72^{\circ}$, the albedo appears clearly brighter than at $61^{\circ}$. Although this may well be only a result of metamorphism during the night, it also fits the pattern that high sun encounters more dark 
(a)
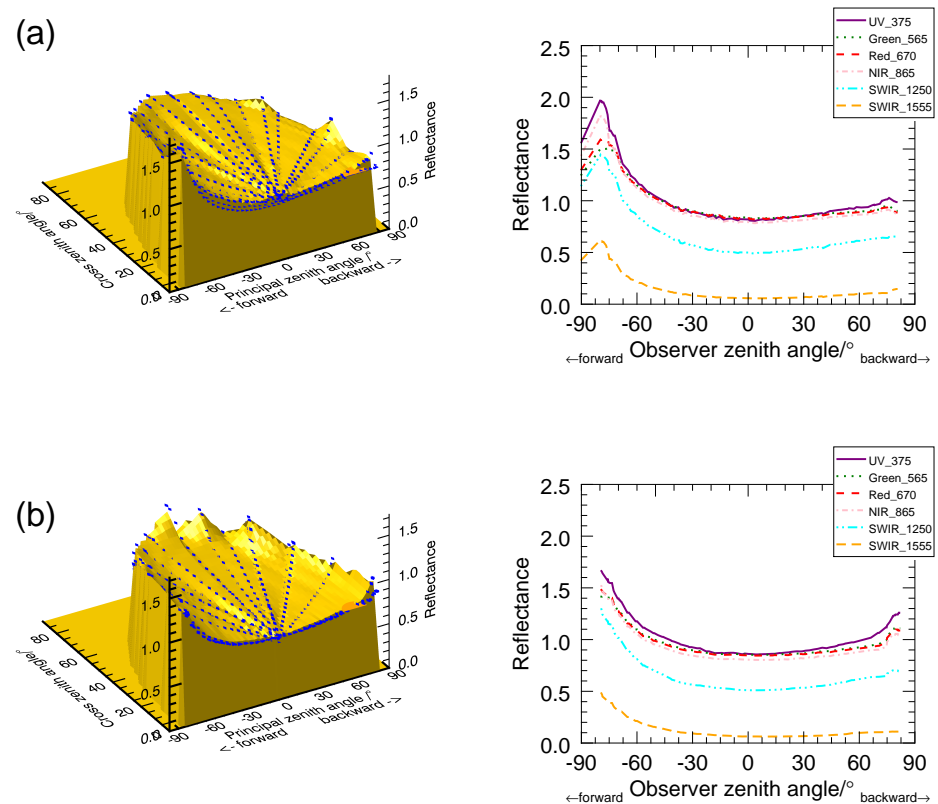

(b)

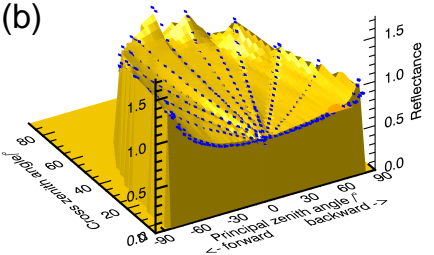

(c)

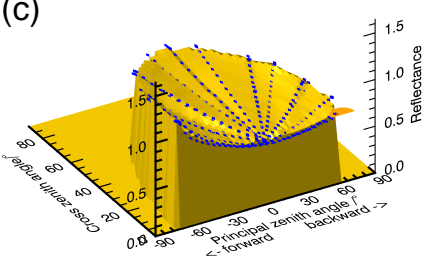

(d)
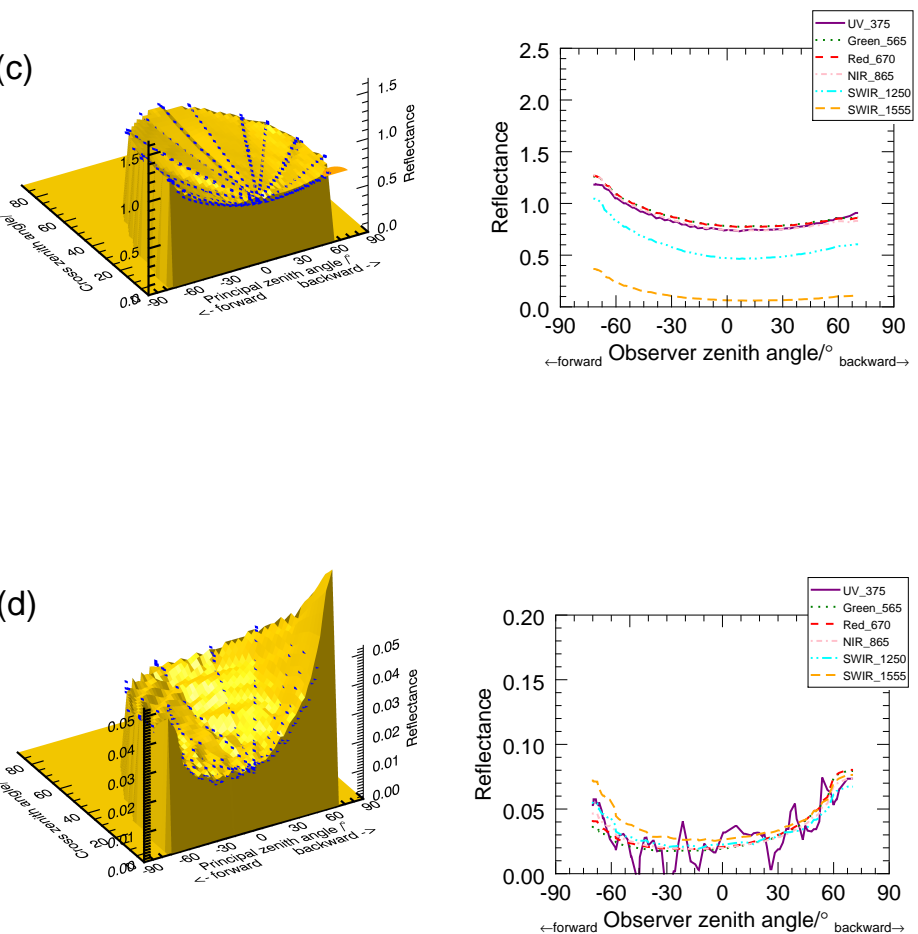
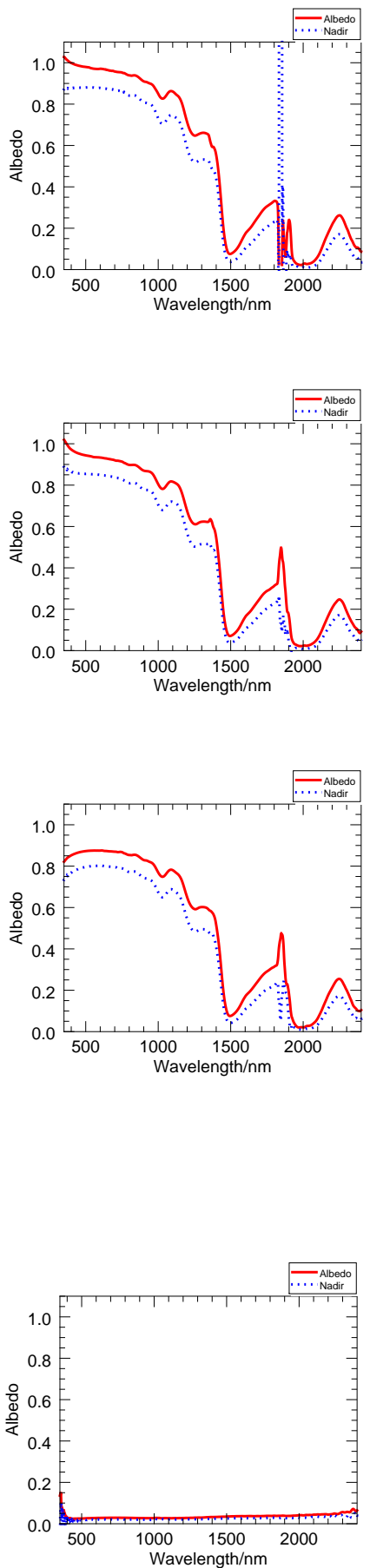

Figure 9. Left: BRF as a function of the observation direction integrated over the spectral range. Middle: The bidirectional reflectance factor (BRF) in the principal plane, at six wavelengths. Right: spectral albedo and BRF at nadir. (a) Natural snow 3 April 2013 11:33, solar zenith angle $63^{\circ}$, (b) snow covered with volcanic sand, $8 \mathrm{~g} / 0.5 \mathrm{~m}^{2}, 3$ April $2013,12: 25,62^{\circ}$, (c) snow covered with volcanic sand, $8 \mathrm{~g} / 0.5 \mathrm{~m}^{2}, 3$ April $201313: 23,62^{\circ}$, (d) pure volcanic sand measured in laboratory.

impurities than low sun, if the heating sinks dark material downwards.

Spectrally, the contaminants darken the snow mostly in the visual bands. The soot, silt, and volcanic sand used here have a smooth (grey) spectrum without significant features. The volcanic sand is darker than snow in all wavelengths (Fig. 9), while the silt may be even brighter in the deepest absorption bands of snow around 1500 and $2000 \mathrm{~nm}$. As expected, at 
(a)
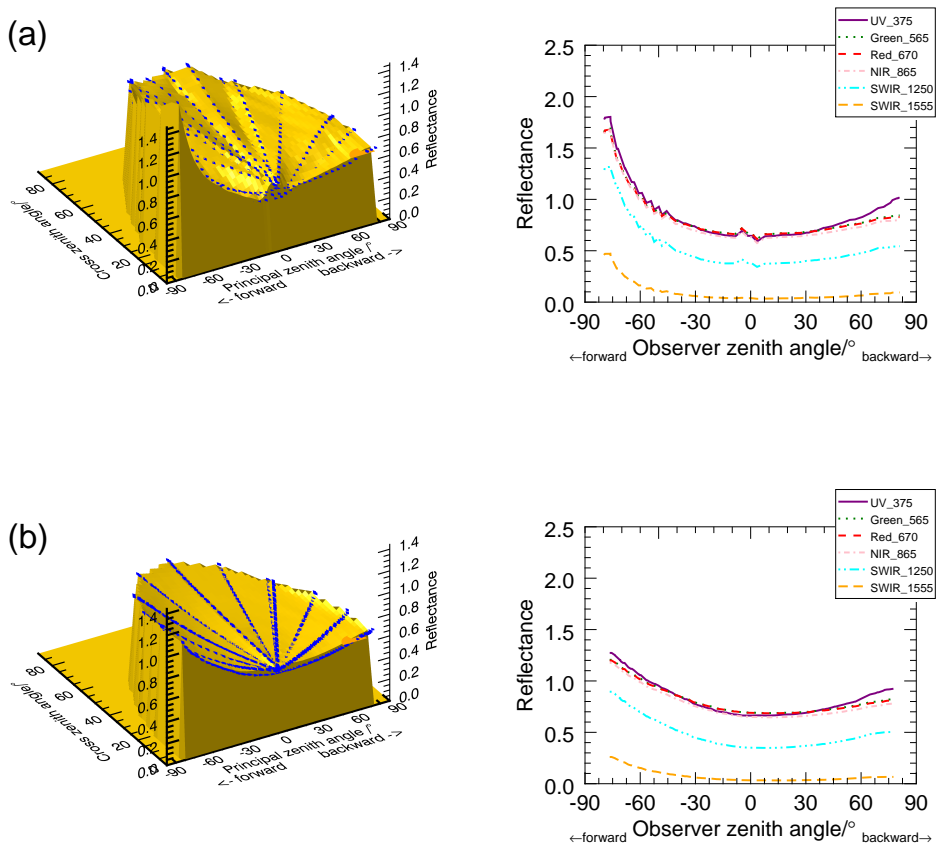

(b)

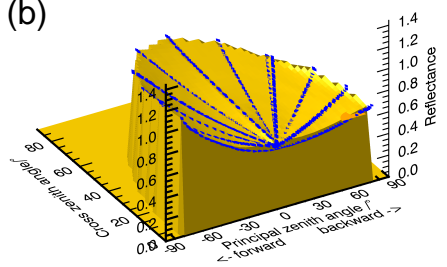

(c)
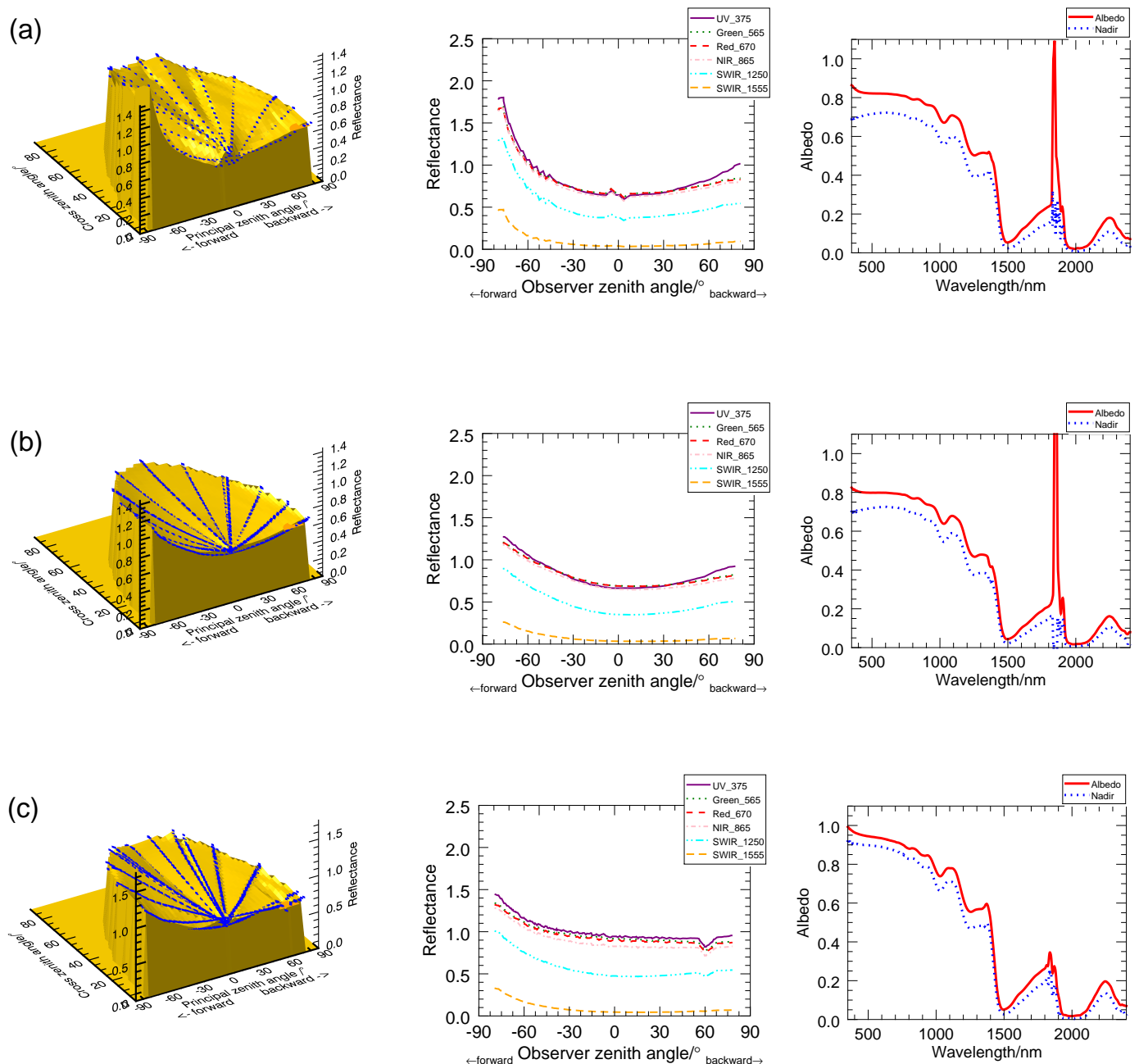
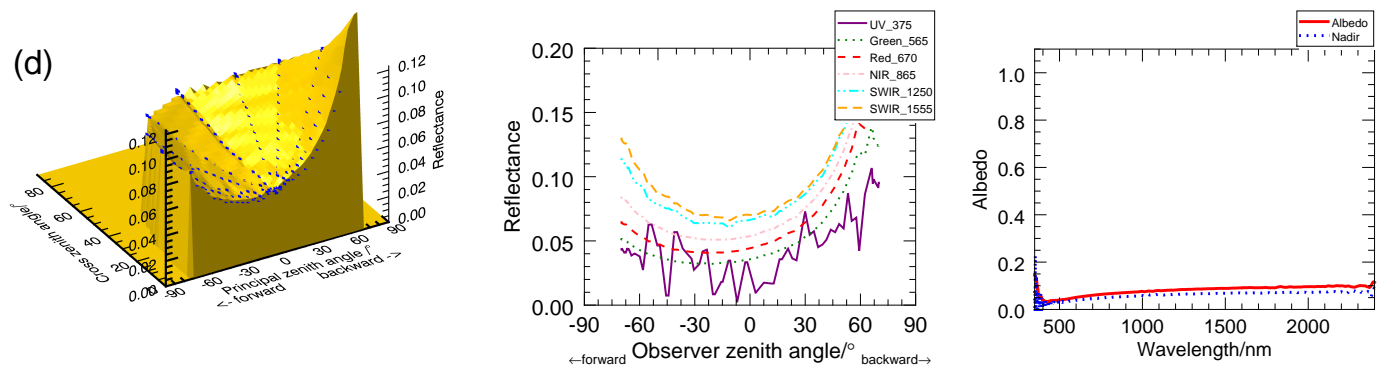

Figure 10. As in Fig. 9. Sooted snow on the 4 April 2013. Panel (a) shows the measurement which started at $09: 56$ with $68^{\circ}$ solar zenith angle; (b) $10: 31,62^{\circ}$; (c) $11: 18,63^{\circ}$; and (d) the natural snow sample at $13: 31,62^{\circ}$.

these dark bands the silt-contaminated snow is brighter than the cleaner snow (Fig. 11). Thus, a spectral signal for impurity inversion exists, but care is needed to separate it from the grain size effect.

From the data, especially Fig. 12, one can see that the clean snow also varies. The reflectance can change by $\pm 10 \%$ in a short time, due to metamorphism. It is not possible to say how clean the clean snow really is. In any case it is too clean to observe the impurities, but it is quite likely that some of the deposited dust may have landed on the clean snow samples, and all possible aerosol and human and animal traces can cause unknown perturbations. An important observation is, however, that adding absorbing impurities enhance melting and metamorphism remarkably. When heated by the sun, the small particles can melt the snow around them, letting them fall down or float up at least several centimetres, depending 
(a)

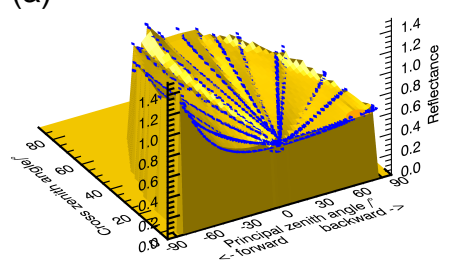

(b)

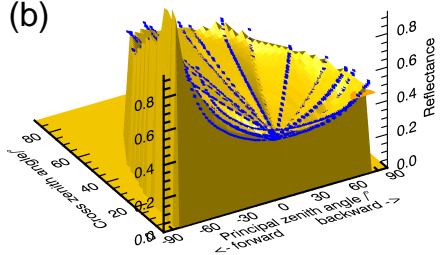

(c)

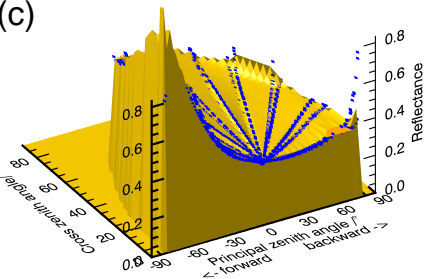

(d)

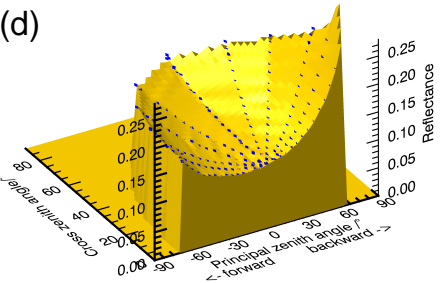

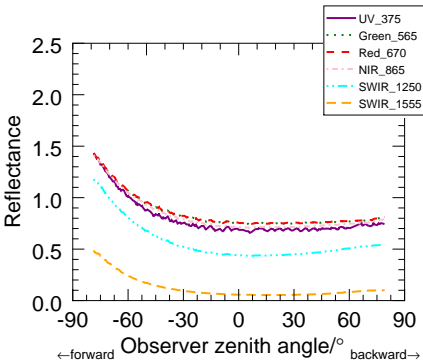
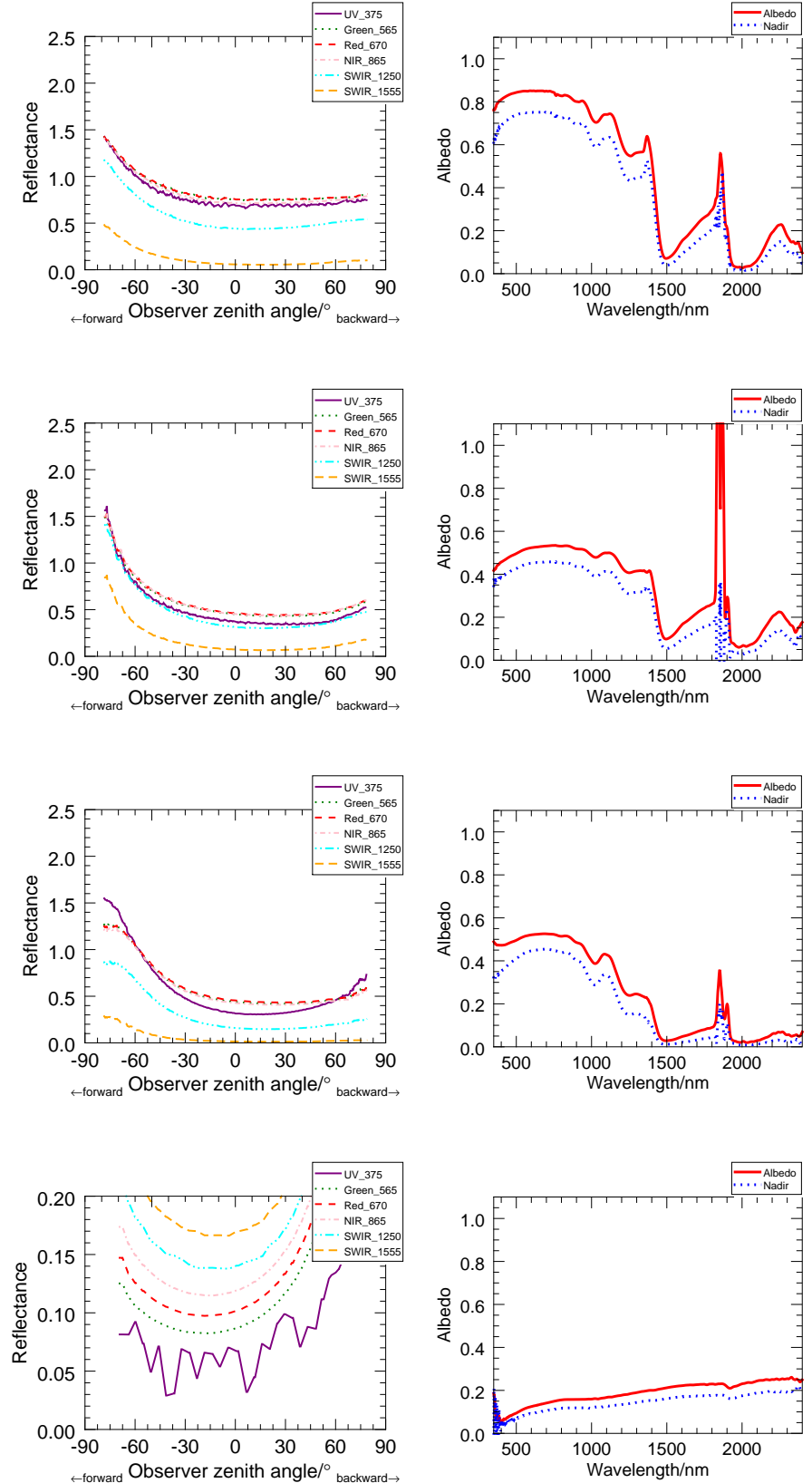

Figure 11. As in Fig. 9. (a) $10 \mathrm{~g}$ of silt/ $0.5 \mathrm{~m}^{2}$ on top of snow, on the 4 April 2013 at 15:05, 65ㅇ (b) $10 \mathrm{~g}$ of silt/ $/ 0.5 \mathrm{~m}^{2}$, on the 4 April 2013 at 16:29, $72^{\circ}$; note large solar zenith angle; (c) same sample on the 5 April 2013 at $11: 16,61^{\circ}$; the difference to $b$ is due to a different solar zenith angle; (d) pure silt measured in the laboratory, $65^{\circ}$.

on their physical properties. This process happens in minutes, and it is thus impossible to say exactly what the state of a sample was upon measuring.

\section{Conclusions}

A field experiment was made to study the effects of different kinds of impurities on the reflectance of snow. Soot collected from chimneys, volcanic sand, and glaciogenic silt were deposited on natural snow surfaces. This simulates both anthropogenic and natural dust sources, both being of importance (Dagsson-Waldhauserova et al., 2015). The bidirectional reflectance factor (BRF) was measured using the Finnish Geodetic Institute field Goniospectropolariradiometer FIGIFIGO.

Impurities make snow darker. However, the concentrations must be rather significant or the spectral signal strong to separate the effects of the contaminants from other snow vari- 
First
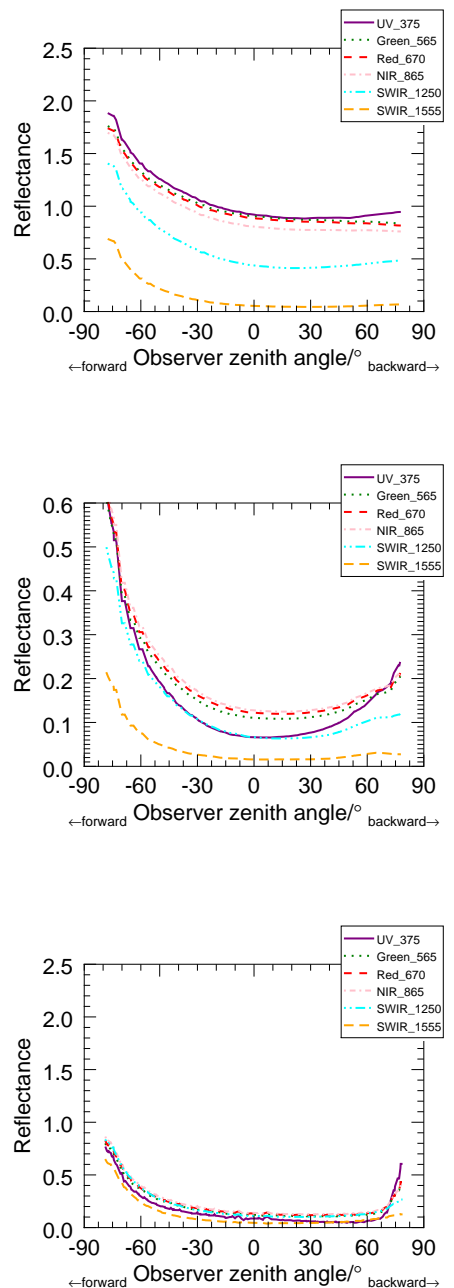

Last
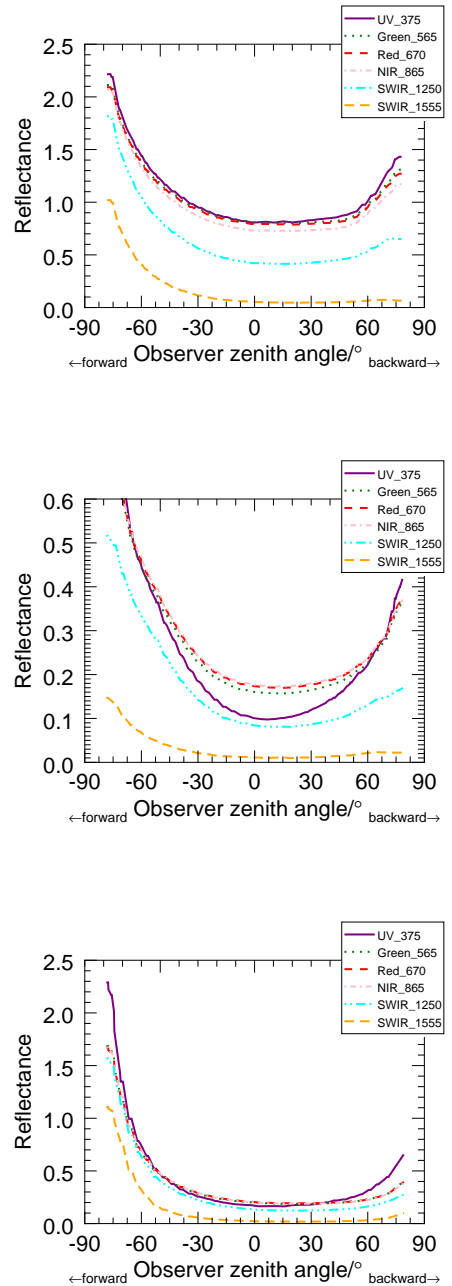

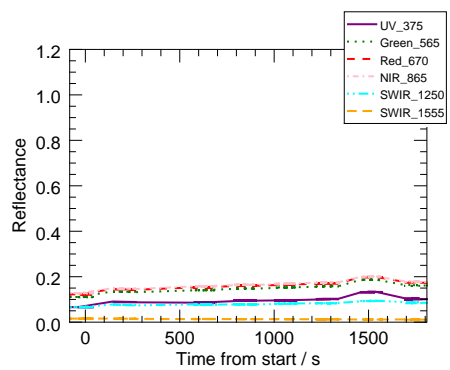

time series at nadir
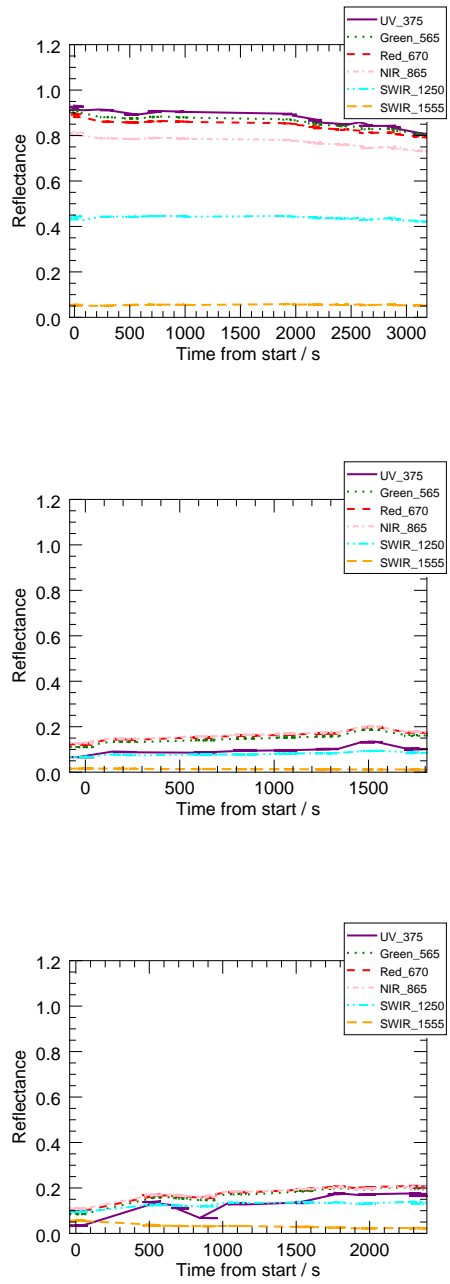

Figure 12. How the reflectance changes during the measurements. Left plots show the reflectance in the principal plane measured in the beginning of a sequence, and the plots in the middle show the same, but measured at the end of the sequence. On the right the reflectance in nadir is shown, taken at different time steps. The top shows untouched snow, the middle shows snow with fine silt $40 \mathrm{~g} / 0.5 \mathrm{~m}{ }^{2}$, taken at $62^{\circ}$, and the bottom plots show snow samples taken at $74^{\circ}$. Untouched snow darkens slightly at nadir and brightens at large zenith angles, while contaminated snow brightens clearly in all directions, especially at large zenith angles.

ations, such as grain size, surface roughness, or snowpack structures, from reflectance data. Typical natural concentrations of black carbon are less than $1 \mathrm{ppm}$, which cannot be detected from optical satellite data without additional information, as already pointed out by Warren (2013).

Snow contaminated with impurities is unstable. When the Sun heats the absorbing particles, they melt or soften the ice around them, allowing the particles to move inside the snow. In this experiment, the particles sank down, leaving the topmost (on a millimetre to centimetre scale) surface whiter than expected. Snow grain size, shape, density, and surface roughness also changed visually. These metamorphism and sinking processes occur so fast that it is difficult to link successive measurements to each other, and to know what was really measured.

After the sinking, the difference between contaminated and clean snow is largest from nadir, where one can still see the dark contaminants through the sink holes, and smallest at large zenith angles, where one sees mostly pure snow. Also the solar zenith angle has a significant effect on what is seen. At small solar zenith angles light goes deeper inside and may interact more with sunk-in impurities than at large zenith angles.

However, different melting conditions, or different hydrophobic properties of the contaminants, may reverse the process, accumulating the dirt on the surface (Conway et al., 1996; Meinander et al., 2014). Such snow was not measured 
here, and must be studied more before wide conclusions are drawn. But in both cases, models assuming a homogeneous distribution of absorbers may over- or underestimate the effect of impurities on the albedo and climate quite significantly.

This experiment aims to fill the gap between laboratory experiments (where one can control the target and measurements optimally) and natural observations (where one measures the targets as they are). In all, we conclude that for modelling snowmelt and spectral albedo affected by lightabsorbing impurities, more experimental results are needed.

Author contributions. A. Virkkula lead the SoS experiment. J. I. Peltoniemi lead BRF measurements, analysed data and compiled the manuscript with contributions from everyone. T. Hakala designed and operated FIGIFIGO. M. Gritsevich planned and performed most of the reflectance measurements and analysed data. J. Svensson participated in the SoS experiment and planning, and contributed significantly to the text, K. Anttila and H.-R. Hannula measured snow surface properties and depth profiles, and G. de Leeuw is the A4 project leader and contributed to the text. O. Meinander was responsible for the original idea and project planning of the A4 project, participated in the preparation of the experiments, and contributed to the manuscript. H. Lihavainen is the MACEB PI, took part of the organization of the SoS experiment and contributed to the text. N. Kivekäs organized the collection of the soot and with A. Virkkula was responsible for the construction and funding of the impurity deposition system of the main experiment. P. Dagsson-Waldhauserová and O. Arnalds provided the volcanic samples and their description.

Acknowledgements. This research has been supported by the Academy of Finland projects 120949, 254195, and 260027, the European Commission ERC Advanced Grant no. 320773 "SAEMPL", COST Actions MP1104 "Polarization", and ES1404 "SNOW", Nordic Top-level Research Initiative (TRI) "CRAICC", Centre on Excellence in Atmospheric Science funded by the Finnish Academy of Sciences Excellence (project 272041), EU LIFE+ project MACEB (project LIFE09 ENV/FI/000572), Maj and Tor Nessling Foundation (project grants 2012456 and 2013093), by the Act 211 of the Government of the Russian Federation (agreement no. 02.A03.21.0006), and Consti Talotekniikka (who gathered the soot).

Edited by: S. M. Noe

\section{References}

Aoki, T., Aoki, T., Fukabori, M., Hachikubo, A., Tachibana, Y., and Nishio, F.: Effects of snow physical parameters on spectral albedo and bidirectional reflectance of snow, J. Geophys. Res., 105, 10219-10236, 2000.

Bisiaux, M. M., Edwards, R., McConnell, J. R., Albert, M. R., Anschütz, H., Neumann, T. A., Isaksson, E., and Penner, J. E.:
Variability of black carbon deposition to the East Antarctic Plateau, 1800-2000 AD, Atmos. Chem. Phys., 12, 3799-3808, doi:10.5194/acp-12-3799-2012, 2012.

Bond, T. C., Doherty, S. J., Fahey, D. W., Forster, P. M., Berntsen, T., DeAngelo, B. J., Flanner, M. G., Ghan, S., Kärcher, B., Koch, D., Kinne, S., Kondo, Y., Quinn, P. K., Sarofim, M. F., Schultz, M. G., Schulz, M., Venkataraman, C., Zhang, H., Zhang, S., Bellouin, N., Guttikunda, S. K., Hopke, P. K., Jacobson, M. Z., Kaiser, J. W., Klimont, Z., Lohmann, U., Schwarz, J. P., Shindell, D., Storelvmo, T., Warren, S. G., and Zender, C. S.: Bounding the role of black carbon in the climate system: a scientific assessment., J. Geophys. Res.Atmos., 188, 5380-5552, doi:10.1002/jgrd.50171, 2013.

Bourgeois, C. S., Calanca, P., and Ohmura, A.: A field study of the hemispherical directional reflectance factor and spectral albedo of dry snow, J. Geophys. Res., 111, D20108, doi:10.1029/2006JD007296, 2006.

Brandt, R. E., Warren, S. G., and Clarke, A. D.: A controlled snowmaking experiment testing the relation between black carbon content and reduction of snow albedo, J. Geophys. Res.-Atmos., 116, D08109, doi:10.1029/2010JD015330, 2011.

Clarke, A. D. and Noone, K. J.: Soot in the Arctic snowpack: a cause for perturbations in radiative transfer, Atmos. Environ., 19, 2045-2053, 1985.

Conway, H., Gades, A., and Raymond, C.: Albedo of dirty snow during conditions of melt, Water Resour. Res., 32, 1713-1718, 1996.

Dagsson-Waldhauserova, P., Arnalds, O., Olafsson, H., Hladil, J., Skala, R., Navratil, T., Chadimova, L., and Meinander, O.: Snowdust storm: unique case study from Iceland, 6-7 March 2013 , Aeol. Res., 16, 69-74, doi:10.1016/j.aeolia.2014.11.001, 2015.

Doherty, S. J., Warren, S. G., Grenfell, T. C., Clarke, A. D., and Brandt, R. E.: Light-absorbing impurities in Arctic snow, Atmos. Chem. Phys., 10, 11647-11680, doi:10.5194/acp-1011647-2010, 2010.

Dumont, M., Brun, E., Picard, G., Michou, M., Libois, Q., Petit, J.R., Geyer, M., Morin, S., and Josse, B.: Contribution of lightabsorbing impurities in snow to Greenland's darkening since 2009, Nat. Geosci., 7, 509-512, doi:10.1038/ngeo2180, 2014.

Fierz, C., Armstrong, R., Durand, Y., Etchevers, P., Greene, E., McClung, D., Nishimura, K., Satyawali, P., and Sokratov, S.: The International Classification for Seasonal Snow on the Ground, no. 83 in IHP-VII Technical Documents in Hydrology, IACS Contribution No. 1, UNESCO-IHP, Paris, 2009.

Flanner, M. G., Zender, C. S., Randerson, J. T., and Rasch, P. J.: Present-day climate forcing and response from black carbon in snow, J. Geophys. Res.-Atmos., 112, D11202, doi:10.1029/2006JD008003, 2007.

Forsström, S., Ström, J., Pedersen, C. A., Isaksson, E., and Gerland, S.: Elemental carbon distribution in Svalbard snow, J. Geophys. Res., 114, D19112, doi:10.1029/2008JD011480, 2009.

Hadley, O. L. and Kirchstetter, T. W.: Black-carbon reduction of snow albedo, Nature Clim. Change, 2, 437-440, doi:10.1038/NCLIMATE1433, 2012.

Hakala, T., Suomalainen, J., and Peltoniemi, J. I.: Acquisition of bidirectional reflectance factor dataset using a micro unmanned aerial vehicle and a consumer camera, Remote Sens., 3, 819-832, doi:10.3390/rs2030819, 2010. 
Hakala, T., Riihelä, A., Lahtinen, P., and Peltoniemi, J. I.: Hemispherical-directional reflectance measurements of snow on the Greenland ice sheet during the radiation, snow characteristics and albedo at Summit (RASCALS) campaign, J. Quant. Spectrosc. Ra., 146, 376-390, 2014.

Hapke, B.: Theory of Reflectance and Emittance Spectroscopy, Cambridge University Press, Cambridge, 180-220, 1993.

Kaasalainen, S., Kaasalainen, M., Mielonen, T., Suomalainen, J., Peltoniemi, J., and Näränen, J.: Optical properties of snow in hotspot region, J. Glaciol., 574-584, 2006.

Kaspari, S. D., Schwikowski, M., Gysel, M., Flanner, M. G., Kang, S., Hou, S., and Mayewski, P. A.: Recent increase in black carbon concentrations from a Mt. Everest ice core spanning 1860-2000 AD, J. Geophys. Res., 38, L04703, doi:10.1029/2010GL046096, 2011.

Kokhanovsky, A.: Spectral reflectance of solar light from dirty snow: a simple theoretical model and its validation, The Cryosphere, 7, 1325-1331, doi:10.5194/tc-7-1325-2013, 2013.

Lyapustin, A., Gatebe, C. K., Kahn, R., Brandt, R., Redemann, J., Russell, P., King, M. D., Pedersen, C. A., Gerland, S., Poudyal, R., Marshak, A., Wang, Y., Schaaf, C., Hall, D., and Kokhanovsky, A.: Analysis of snow bidirectional reflectance from ARCTAS Spring-2008 Campaign, Atmos. Chem. Phys., 10, 4359-4375, doi:10.5194/acp-10-4359-2010, 2010.

McConnell, J. R., Edwards, R., Kok, G. L., Flanner, M. G., Zender, C. S., Salzman, E. S., Banta, J. R., Pasteris, D. R., Carter, M. M., and Kahl, J. D. W.: 20th century industrial black carbon emissions altered arctic climate forcing, Science, 317, 1381-1384, 2007.

Meinander, O., Kazadzis, S., Arola, A., Riihelä, A., Räisänen, P., Kivi, R., Kontu, A., Kouznetsov, R., Sofiev, M., Svensson, J., Suokanerva, H., Aaltonen, V., Manninen, T., Roujean, J.-L., and Hautecoeur, O.: Spectral albedo of seasonal snow during intensive melt period at Sodankylä, beyond the Arctic Circle, Atmos. Chem. Phys., 13, 3793-3810, doi:10.5194/acp-13-37932013, 2013.

Meinander, O., Kontu, A., Virkkula, A., Arola, A., Backman, L., Dagsson-Waldhauserová, P., Järvinen, O., Manninen, T., Svensson, J., de Leeuw, G., and Leppäranta, M.: Brief communication: Light-absorbing impurities can reduce the density of melting snow, The Cryosphere, 8, 991-995, doi:10.5194/tc-8-9912014, 2014.

Ming, J., Cachier, H., Xiao, C., Qin, D., Kang, S., Hou, S., and $\mathrm{Xu}$, J.: Black carbon record based on a shallow Himalayan ice core and its climatic implications, Atmos. Chem. Phys., 8, 13431352, doi:10.5194/acp-8-1343-2008, 2008.

Nicodemus, F. E., Richmond, J. C., Hsia, J. J., Ginsberg, I. W., and Limperis, T.: Geometrical considerations and nomenclature for reflectance, Tech. rep., Institute for Basic Standards, National Bureau of Standards, Washington DC, USA, 1977.

Painter, T. H., Dozier, J., Roberts, D. A., Davis, R. E., and Green, R. O.: Retrieval of subpixel snow-covered area and grain size from imaging spectrometer data, Remote Sens. Environ., 85, 64-77, 2003.

Peltoniemi, J., Hakala, T., Suomalainen, J., and Puttonen, E.: Polarised bidirectional reflectance factor measurements from snow, soil and gravel, J. Quant. Spectrosc. Ra., 110, 1940-1953, doi:10.1016/j.jqsrt.2009.04.008, 2009.
Peltoniemi, J., Gritsevich, M., and Puttonen, E.: Reflectance and polarisation characteristics of various vegetation types, in: Light Scattering Reviews, vol. 9, edited by: Kokhanovsky, A., Springer praxis books, Heidelberg, doi:10.1007/978-3-642-37985-7_7, 257-294, 2015.

Peltoniemi, J. I.: Spectropolarised ray-tracing simulations in densely packed particulate medium, J. Quant. Spectrosc. Ra., 108, 180-196, 2007.

Peltoniemi, J. I., Manninen, T., Suomalainen, J., Hakala, T., Puttonen, E., and Riihelä, A.: Land surface albedos computed from BRF measurements with a study of conversion formulae, Remote Sens., 2, 1918-1940, doi:10.3390/rs2081918, 2010a.

Peltoniemi, J. I., Suomalainen, J., Hakala, T., Puttonen, E., Näränen, J., Kaasalainen, S., Torppa, J., and Hirschmugl, M.: Reflectance of various snow types: measurements, modelling and potential for snow melt monitoring, chap. 9, in: Light Scattering Reviews 5: Single Light Scattering and Radiative Transfer, edited by: Kokhanovsky, A. A., Springer Praxis Books, Heidelberg, doi:10.1007/978-3-642-10336-0, 393-450, 2010 b.

Peltoniemi, J. I., Hakala, T., Suomalainen, J., Honkavaara, E., Markelin, L., Gritsevich, M., Eskelinen, J., Jaanson, P., and Ikonen, E.: A detailed study for the provision of measurement uncertainty and traceability for goniospectrometers, J. Quant. Spectrosc. Ra., 146, 376-390, 2014.

Piironen, J., Muinonen, K., Keränen, S., Karttunen, H., and Peltoniemi, J. I.: Backscattering of light from snow: field measurements, in: Observing Land From Space: Science, Customers and Technology, vol. 4 of Advances in Global Change Research, edited by: Verstraete, M. M., Menenti, M., and Peltoniemi, J. I., 219-228, Kluwer, Dordrecht, the Netherlands, 2000.

Räisänen, P., Kokhanovsky, A., Guyot, G., Jourdan, O., and Nousiainen, T.: Parameterization of single-scattering properties of snow, The Cryosphere Discuss., 9, 873-926, doi:10.5194/tcd-9873-2015, 2015.

Sasse, C. and Peltoniemi, J. I.: Angular scattering measurements and calculations of rough spherically shaped carbon particles, in: Opt. Sci., and Sci. Instr., SPIE, doi:10.1117/12.218329, 1995.

Suomalainen, J., Hakala, T., Peltoniemi, J., and Puttonen, E.: Polarised multiangular reflectance measurements using Finnish Geodetic Institute Field Goniospectrometer, Sensors, 9, 38913907, doi:10.3390/s90503891, 2009.

Svensson, J., Ström, J., Hansson, M., and Lihavainen, H.: Observed metre scale horizontal variability of elemental carbon in surface snow, Environ. Res. Lett., 8, 034012, doi:10.1088/17489326/8/3/034012, 2013.

Svensson, J., Virkkula, A., Meinander, O., Kivekäs, N., Hannula, H.-R., Järvinen, O., Peltoniemi, J. I., Gritsevich, M., Heikkilä, A., Kontu, A., Hyvärinen, A.-P., Neitola, K., Brus, D., Dagsson-Waldhauserova, P., Anttila, K., Hakala, T., Kaartinen, H., Vehkamäki, M., de Leeuw, G., and Lihavainen, H.: Soot on snow experiments: light-absorbing impurities effect on the natural snowpack, The Cryosphere Discuss., 9, 1227-1267, doi:10.5194/tcd-9-1227-2015, 2015.

Tanikawa, T., Aoki, T., Hori, M., Hachikubo, A., and Aniya, M.: Snow bidirectional reflectance model using non-spherical snow particles and its validation with field measurements, EARSeL eProceedings, 5, 137-145, 2006.

Tanikawa, T., Hori, M., Aoki, T., Hachikubo, A., Kuchiki, K., Niwano, M., Matoba, S., Yamaguchi, S., and Stamnes, K.: In 
situ measurements of polarization properties of snow surface under the Brewster geometry in Hokkaido, Japan, and northwest Greenland ice sheet, J. Geophys. Res., 119, 13946-13964, doi:10.1002/2014JD022325, 2014.

Warren, S.: Can black carbon in snow be detected by remote sensing?, J. Geophys. Res.-Atmos., 118, 779-786, 2013.

Warren, S. and Wiscombe, W.: A model for spectral albedo of snow II: Snow containing atmospheric aerosols, J. Atmos. Sci., 37, 2734-2747, 1980.
Wiscombe, W. and Warren, S.: A model for spectral albedo of snow I: Pure snow, J. Atmos. Sci., 37, 2712-2733, 1980.

Xu, B., Cao, J., Hansen, J., Yao, T., Joswiak, D., Wang, N., Wu, G., Wang, M., Zhao, H., Yang, W., Liu, X., and He, J.: Black soot and the survival of Tibetan glaciers, P. Natl. Acad. Sci. USA, 106, 22114-22118, 2009. 